\title{
"Health Is on the Back Burner:" Multilevel Barriers and Facilitators to Primary Care Among People Who Inject Drugs
}

\author{
Delia Motavalli, BS ${ }^{7}$, Jessica L. Taylor, $M D^{2,3}$, Ellen Childs, PhD, MA 4 , \\ Pablo K. Valente, MD, MPH ${ }^{5}$, Peter Salhaney, ScM ${ }^{5,6}$, Jennifer Olson, MBA', \\ Dea L. Biancarelli, MS 4 , Alberto Edeza, BS, BA ${ }^{5,6}$, Joel J. Earlywine, MS4, \\ Brandon D. L. Marshall, PhD ${ }^{7}$, Mari-Lynn Drainoni, PhD, Med 4,8,9,10, \\ Matthew J. Mimiaga, SCD, MPH ${ }^{5,6,7,17,12}$, Katie B. Biello, PhD, MPH $5,6,7,17$, and \\ Angela R. Bazzi, PhD, MPH ${ }^{13}$ (D)
}

\begin{abstract}
'Boston University School of Medicine, Boston, MA, USA; '2Section of General Internal Medicine, Department of Medicine, Boston University School of Medicine, Boston, MA, USA; ${ }^{3}$ Grayken Center for Addiction, Boston Medical Center, Boston, MA, USA; ${ }^{4}$ Department of Health Law, Policy \& Management, Boston University School of Public Health, Boston, MA, USA; ${ }^{5}$ Department of Behavioral and Social Sciences, Brown University School of Public Health, Providence, RI, USA; ${ }^{6}$ Center for Health Equity Research, Brown University, Providence, RI, USA; ${ }^{7}$ Department of Epidemiology, Brown University School of Public Health, Providence, RI, USA; ${ }^{8}$ Section of Infectious Diseases, Department of Medicine, Boston University School of Medicine, Boston, MA, USA; ${ }^{9}$ Evans Center for Implementation and Improvement Sciences, Boston University School of Medicine, Boston, MA, USA; ${ }^{10}$ Center for Healthcare Organization and Implementation Research, ENRM VA Hospital, Bedford, MA, USA; " The Fenway Institute, Fenway Health, Boston, MA, USA; ${ }^{12}$ Department of Psychiatry and Human Behavior, Brown University Alpert Medical School, Providence, RI, USA; ${ }^{13}$ Department of Community Health Sciences, Boston University School of Public Health, Boston, MA, USA.
\end{abstract}

BACKGROUND: The estimated 2.2 million people who inject drugs (PWID) in the USA experience significant gaps in preventive healthcare and a high burden of infectious, psychiatric, and other chronic diseases. Many PWID rely on emergency medical services, which are costly and not designed to deliver preventive services, manage chronic conditions, or address social needs.

OBJECTIVE: The objective of this study was to explore barriers and facilitators to primary care utilization from the perspectives of PWID in New England, a region highly affected by the overdose crisis.

DESIGN: Participants completed semi-structured qualitative interviews exploring substance use and healthcare utilization patterns.

PARTICIPANTS: We recruited 78 PWID through community-based organizations (e.g., syringe service programs) in 16 urban and non-urban communities throughout Massachusetts and Rhode Island.

APPROACH: Thematic analysis identified barriers and facilitators to primary care utilization at the individual, interpersonal, and systemic levels.

KEY RESULTS: Among 78 PWID, 48 described recent primary care experiences; 33 had positive experiences and 15 described negative experiences involving discrimination or mistrust. Individual-level barriers to primary care utilization included perceived lack of need and competing priorities (e.g., avoiding opioid withdrawal, securing shelter beds). Interpersonal-level barriers included

Prior Presentations N/A.

Electronic supplementary material The online version of this article (https://doi.org/10.1007/s11606-020-06201-6) contains supplementary material, which is available to authorized users.

Received April 30, 2020

Accepted August 27, 2020

Published online September 11, 2020 stigma and perceived low quality of care for PWID. Systemic-level barriers included difficulty navigating healthcare systems, inadequate transportation, long wait times, and frequent provider turnover. Participants with positive primary care experiences explained how appointment reminders, flexible hours, addiction medicinetrained providers, case management services, and transportation support facilitated primary care utilization and satisfaction.

CONCLUSIONS: Findings regarding the multilevel barriers and facilitators to accessing primary care among PWID identify potential targets for programmatic interventions to improve primary care utilization in this population. Based on these findings, we make recommendations for improving the engagement of PWID in primary care as a means to advance individual and public health outcomes.

KEY WORDS: substance-related disorders; preventive health services; primary health care; social stigma; patient acceptance of health care; quality of health care.

J Gen Intern Med 36(1):129-37

DOI: $10.1007 / \mathrm{s} 11606-020-06201-6$

(c) Society of General Internal Medicine 2020

\section{INTRODUCTION}

The opioid and stimulant use disorder epidemics are driving unprecedented rates of injection drug use in the USA. ${ }^{1,2}$ In addition to the acute complications of overdose and deep tissue infections, ${ }^{3,4}$ people who inject drugs (PWID) experience an outsized burden of chronic disease and significant gaps in access to preventive healthcare. 
Rates of chronic viral infection (e.g., HIV, viral hepatitis), ${ }^{5,6}$ psychiatric illness, ${ }^{7,8}$ and cardiopulmonary disease ${ }^{9}$ are all higher among PWID than the general population, and uncontrolled substance use disorder (SUD) complicates management of chronic illness. ${ }^{10,11}$ Simultaneously, access to preventive services is woefully inadequate. Women who inject drugs are more likely to rely on ineffective contraception, ${ }^{12,13}$ and have high rates of unintended pregnancy ${ }^{14}$ and sexually transmitted infections. ${ }^{15}$ Hepatitis A and B vaccinations are recommended for all PWID; ${ }^{9}$ however, few PWID have received them. ${ }^{16}$ Hepatitis C screening and treatment rates also remain low ${ }^{17,18}$ in spite of screening recommendations for all persons at high risk of infection, ${ }^{9}$ and HIV pre-exposure prophylaxis (PrEP) uptake among PWID lags behind other high-risk populations. ${ }^{19,20}$

Research suggests that primary care is effective for addressing many of the complex health needs of PWID. ${ }^{21}$ In addition to vaccines, contraception, sexually transmitted infection screening, and PrEP, primary care providers (PCPs) increasingly offer screening and treatment for hepatitis $\mathrm{C}$ and access to medications for opioid use disorder (MOUD). ${ }^{22,23}$ For example, PCPs may offer referrals to methadone or provide on-site access to buprenorphine or naltrexone. ${ }^{24}$ In fact, PWID engaged in primary care are more likely to initiate and maintain MOUD ${ }^{25,26}$ and abstain from drug use. ${ }^{21}$

Despite the benefits of primary care, PWID have low primary care utilization ${ }^{27,28}$ and frequently access emergency medical services for conditions that could be addressed in primary care settings. ${ }^{29,30}$ Emergency departments have developed innovative protocols to address the unmet needs of PWID accessing emergency services. ${ }^{31,32}$ However, emergency departments are not designed or resourced for delivering preventive services, providing long-term management of SUD and other chronic conditions, or addressing social needs. In contrast, primary care settings offer increased provider continuity and are associated with improved treatment adherence and disease prevention. ${ }^{33}$

PWID injecting daily and those with low weekly income are less likely to access primary care ${ }^{34}$ and PWID may avoid traditional healthcare settings due to past experiences of stigma. ${ }^{35,36}$ Despite this growing body of research, the reasons for low primary care utilization among U.S. PWID are not fully understood. To explore factors influencing primary care utilization in PWID and identify related intervention targets, we drew from an in-depth qualitative study involving communityrecruited individuals reporting recent and ongoing injection of opioids and other drugs. Findings have implications for improving primary care engagement in this growing yet medically underserved population.

\section{METHODS}

\section{Study Design and Sample}

We drew from a two-phase HIV prevention-focused qualitative study with PWID in the Northeast US, a region that has had significant public health consequences of opioid and polysubstance use. ${ }^{37-39}$ The first phase (2016-2017) involved interviews with PWID in Boston, MA, and Providence, RI. ${ }^{40}$ The second phase (2018-2019) was conducted in 14 nonurban communities throughout both states that were selected due to a high burden of opioid-related mortality and morbidity including infectious disease transmission. To recruit PWID in all locations, we partnered with local community-based organizations (CBOs; e.g., syringe-service programs [SSPs], dropin HIV/hepatitis C testing centers). CBO staff informed interested individuals about the research, and research staff then conducted screening for eligibility which included being $\geq$ 18 years, speaking English, and self-reporting HIV-uninfected status and past-month injection of any drugs. We used purposeful sampling to recruit individuals with diversity in age, gender, and HIV-related risk behaviors. ${ }^{41,42}$ Participants provided informed consent and received \$25 for participating. The Brown and Boston University Institutional Review Boards approved all study protocols and provided a waiver of documentation of consent.

\section{Data Collection}

In private spaces within $\mathrm{CBOs}$, trained interviewers administered brief quantitative surveys to assess socio-demographics (e.g., age, gender, race), health insurance status, and sexual and substance use behaviors that increase the risk for HIV transmission. Trained interviewers used a semi-structured interview guide (see Supplementary file) developed by our team of interdisciplinary HIV prevention-focused researchers that included open-ended questions designed to explore health risk behaviors and prevention needs. General health concerns and healthcare utilization emerged as important topics in the first phase of our research; we thus added related questions and probes for the second phase. Interviews lasted approximately 45-60 min and were audio-recorded and professionally transcribed. Throughout the study period, the entire research team (including lead investigators and interviewers) met weekly to discuss emerging topics and determine whether thematic saturation had been achieved in key topics of interest regarding HIV risk and prevention. ${ }^{43}$

\section{Data Analysis}

During weekly meetings, team members reviewed interview transcripts to identify preliminary codes and draft codebooks using a collaborative process previously detailed. ${ }^{40}$ Briefly, potential codes were based on interview guide domains and emergent topics. Team members independently tested preliminary codebooks on sets of transcripts and then met to discuss coding progress, assess coding discrepancies across analysts, and agree upon codebook revisions. This process was repeated several times until team members reached consensus on final parent codes, sub-codes, and code definitions. A team of core analysts then applied finalized codes to transcripts using NVivo (v12). A lead analyst assessed the consistency of 
coding across analysts and held weekly calls to monitor coding progress, address questions and discrepancies, and identify themes. Although we developed two codebooks, one for each phase of the study, final codebooks and analytical processes overlapped substantially, contributing to a high degree of consistency across both phases.

For this analysis, we reviewed data from codes on "Health Services" and "Health Status" (both phases) and "Primary Care/Preventative" and "Health Conditions" (new codes developed in phase 2). We then stratified participants based on primary care utilization and conducted in-depth comparative analyses, identifying barriers to primary care among those without it, challenges and facilitators of access among those with recent experiences, and reasons for satisfaction among those describing positive experiences. We drew from the socioecological model to organize multilevel barriers and facilitators to primary care utilization. ${ }^{44}$ Findings are illustrated using representative quotes.

\section{RESULTS}

\section{Participant Characteristics, Health Concerns, and Healthcare Utilization}

Among 78 PWID, the median age was 37 years (range 20-62), and $47(60 \%)$ identified as male (Table 1). In brief quantitative surveys, most (65\%) reported injecting at least daily, with the most common substances injected being heroin $(92 \%)$, fentanyl $(80 \%)$, cocaine $(64 \%)$, crack $(33 \%)$, and methamphetamine (22\%). Most participants (94\%) had public insurance.

When asked in qualitative interviews about their most important health concerns, many participants discussed the fear of overdose and HIV acquisition as well as infections such as abscess, cellulitis, and endocarditis. Most had been diagnosed with hepatitis $\mathrm{C}$ but few were concerned about it and many chose to delay treatment. Finally, many participants discussed depression, anxiety, and other psychiatric illnesses.

In qualitative interviews, participants described diverse patterns of healthcare utilization, and all but three mentioned primary care in their interviews. Of the 75 participants who mentioned primary care, 27 stated that they did not use it and instead relied on emergency services or avoided healthcare altogether. The remaining 48 participants discussed having recent primary care experiences; among those, 33 described positive experiences with primary care and 15 described negative experiences. Within these varied experiences, we identified interrelated, multilevel barriers, and facilitators to accessing primary care.

\section{Individual-Level Factors Influencing Primary Care Utilization}

At the individual level, barriers to accessing primary care included (1) perceived lack of need and (2) difficulty keeping appointments due to competing priorities. First, while many
Table 1 Characteristics of the Study Sample of People Who Inject Drugs in Urban and Non-Urban Communities in Massachusetts and Rhode Island, 2016-2019 $(n=78)$

\begin{tabular}{|c|c|}
\hline & $n(\%)$ \\
\hline \multicolumn{2}{|l|}{ Location } \\
\hline Massachusetts & $49(63)$ \\
\hline Rhode Island & $29(37)$ \\
\hline Age, in years; median (interquartile range) & $37(30-43)$ \\
\hline \multicolumn{2}{|l|}{ Race (not mutually exclusive) } \\
\hline American Indian or Alaska Native & $3(4)$ \\
\hline Black or African American & $9(12)$ \\
\hline White & $59(76)$ \\
\hline Other & $13(17)$ \\
\hline Ethnicity: Hispanic/Latino & $16(21)$ \\
\hline \multicolumn{2}{|l|}{ Current gender identity } \\
\hline Male & $47(60)$ \\
\hline Female & $29(37)$ \\
\hline Male to female transgender & $1(1)$ \\
\hline Genderqueer & $1(1)$ \\
\hline \multicolumn{2}{|l|}{ Sexual orientation $(n=77) *$} \\
\hline Heterosexual or straight & $56(72)$ \\
\hline Homosexual or gay & $5(6)$ \\
\hline Bisexual & $15(19)$ \\
\hline Queer & $1(1)$ \\
\hline \multicolumn{2}{|l|}{ Educational attainment } \\
\hline Less than high school & $19(24)$ \\
\hline High school or GED & $27(35)$ \\
\hline Some college (no degree) & $26(33)$ \\
\hline Completed college & $6(8)$ \\
\hline \multicolumn{2}{|l|}{ Employment status (not mutually exclusive) } \\
\hline Employed fulltime $(30+\mathrm{h} /$ week $)$ & $7(9)$ \\
\hline Employed part-time $(<30 \mathrm{~h} /$ week $)$ & $5(6)$ \\
\hline Unemployed & $49(63)$ \\
\hline Disabled & $16(21)$ \\
\hline Retired & $1(1)$ \\
\hline Fulltime student & $1(1)$ \\
\hline Part-time student & $1(1)$ \\
\hline Health insurance: has health insurance & $75(96)$ \\
\hline Has public health insurance & $73(94)$ \\
\hline Ever diagnosed with hepatitis C & $55(71)$ \\
\hline \multicolumn{2}{|c|}{ Substances used to get "high," past 3 months (not mutually exclusive) } \\
\hline Alcohol & $34(44)$ \\
\hline Heroin & $73(94)$ \\
\hline Fentanyl, or other synthetic opioid $(n=45) * *$ & $38(84) * *$ \\
\hline Other opioids like prescription painkillers & $23(29)$ \\
\hline Non-prescribed (i.e., "street") methadone & $11(14)$ \\
\hline Cocaine & $61(78)$ \\
\hline Crack & $53(68)$ \\
\hline Crystal methamphetamine & $21(27)$ \\
\hline Poppers (i.e., amyl nitrate) & $4(5)$ \\
\hline Marijuana & $55(71)$ \\
\hline Downers or sedatives (e.g., Valium, Ativan, Xanax) & $41(53)$ \\
\hline Other drugs, not prescribed & $25(32)$ \\
\hline \multicolumn{2}{|l|}{ Frequency of drug injection, past 3 months } \\
\hline Less than once per month & $2(3)$ \\
\hline $1-3$ days per month & $8(10)$ \\
\hline Once per week & $1(1)$ \\
\hline 2-6 days per week & $16(21)$ \\
\hline Once per day every day & $5(6)$ \\
\hline $2-3$ times per day every day & $27(35)$ \\
\hline 4 or more times per day every day & $19(24)$ \\
\hline \multicolumn{2}{|l|}{ Drugs injected, past 3 months (not mutually exclusive) } \\
\hline Heroin & $72(92)$ \\
\hline Fentanyl, or other synthetic opioids $(n=45)^{* *}$ & $36(80) * *$ \\
\hline Other opioids like prescription painkillers & $7(9)$ \\
\hline Methadone & $1(1)$ \\
\hline Cocaine & $50(64)$ \\
\hline Crack & $26(33)$ \\
\hline Crystal methamphetamine & $17(22)$ \\
\hline Downers or sedatives (e.g., Valium, Ativan, Xanax) & $2(3)$ \\
\hline Other drug or combination of drugs & $19(24)$ \\
\hline
\end{tabular}

*Missing data

**Use of fentanyl or other synthetic opioids was only assessed in the second phase of the research study conducted in non-urban communities (2018-2019) 
participants described serious health concerns, some explained that they did not utilize primary care because they felt healthy and were not worried about their health, such as this 43-yearold man: 'I'm in my early 40's. I'm in good health... I'm not even interested in [primary care], because I can feel myself, my health is good... I'm happy, and that's what's important." Due to drug use, some participants did not perceive a need for primary care, as explained by a 59-year-old man: “I don't feel that there's nothing wrong with me because I'm all high all the time, so feeling just the alcohol and the drugs."

A second individual-level barrier to accessing primary care was competing priorities. Many participants said they cared about their health but were unable to prioritize it. One man described not seeking treatment for a life-threatening brain aneurysm because "health is on the back burner [and] really not a priority when you're actively using drugs." For participants experiencing homelessness, finding shelter and staying warm took precedence. As one woman explained, it is hard to "prioritize your long-term needs [while] living a lifestyle that focuses on daily survival." Homeless shelters' schedules posed additional challenges, as described by a 35 -year-old woman: "A lot of people who are getting high are homeless, and the shelters pretty much do a lottery between certain times. If you're not there, you risk not getting a bed. And it's winter time so... they probably wouldn't go [to the doctor]."

For many participants, obtaining and using drugs to prevent opioid withdrawal were time-consuming competing priorities. Many described a daily cycle of waking up feeling "dope-sick" and struggling to earn money and locate drugs, a process they had to repeat as soon as their high began wearing off. Some injected as many as ten times per day, with one participant asserting, "being an addict is a fulltime job." One 53-year-old man explained how this made it difficult to keep appointments: "If I haven't dosed and I know I'm going to be sick sitting in the doctor's office, I won't even go to the appointment. I'll go and look for heroin just to not to be sick."

Related to these individual-level barriers, participants also described facilitators of accessing primary care. First, several participants preferred flexible or drop-in appointments and wished more clinics offered on-demand services, as explained by this 35-year-old man: "If you could just walk in, that would be better for drug addicts. People [with] any kind of high-risk situation in general [are] probably not the best to keep an appointment." Another participant described good access to primary care, and credited this in part to his physician's flexibility: "He might have me wait a couple hours, but I can get in that day." Some participants were also better able to keep appointments through reminders from clinics or support persons. One man struggled to remember appointments, but saw his PCP with help from his girlfriend: "She's got a calendar for me and fills out days and stuff, so it helps a lot." Others cited smartphones, calls, and text messages as helpful in remembering primary care appointments, like this 27-yearold man: "I get a text message on my phone saying, the day before, when my appointment is... It's awesome." However, others lacked phone access due to difficulties paying bills or their belongings being lost or stolen.

\section{Interpersonal-Level Factors Influencing Primary Care Utilization}

Many participants in our sample avoided healthcare or chose not to disclose their drug use in order to avoid discrimination. One man described how stigma affected his experience with healthcare: "Once they know that you're an IV drug user, they tend to look down on you. You feel like you're not gonna get the level of care that you're expecting, or what you feel you deserve." Despite the pervasiveness of stigma and the barrier it posed for many participants, some overcame it, as explained by this 24-year-old man: "My health is way more important than getting judged... I'm going to get judged everywhere I go." One woman added it was particularly difficult to face stigma when feeling ill: "You already feel like shit... It's just hard. But I learned to swallow it when I really need help."

Participants who had positive experiences with primary care stressed the importance of finding compassionate, nonjudgmental providers. For example, one 41-year-old man met his PCP through a CBO and developed a positive relationship with her: "She's compassionate. She doesn't judge me or nothing.... As long as you're honest with her, she's down and she's real." Some participants described addiction medicine-trained providers as more understanding and able to treat patients "like human[s]." Conversely, if participants believed providers in their area were less knowledgeable about SUDs, they were less likely to utilize primary care. One participant explained her hesitation toward healthcare in her small town because, "they're more familiar with [addiction] in Boston. So, I've never really dealt with any doctors in [this] area."

\section{Systemic-Level Factors Influencing Primary Care Utilization}

Many participants identified challenges relating to the following: (1) difficulty navigating the healthcare system, (2) unreliable transportation, (3) long wait times for appointments, and (4) frequent provider turnover preventing the establishment of trusting relationships. Importantly, many participants described strategies they employed to access primary care in spite of these systemic-level barriers.

First, some participants described difficulty with navigating the healthcare system, including enrolling in insurance and scheduling appointments. One 22-year-old man stated he had no access to healthcare aside from emergency services and did not "know where [he] would start." A 35-year-old woman described how case managers helped address this difficulty: "They help us with all types of things like, 'Hey, I'm really interested on getting on Suboxone. Where do I go for that?' Or, 'Hey, I really need a primary care appointment. Where do I go for that?' And they'll tell you." In addition to helping set up 
appointments, case managers helped motivate some participants, keeping them "on the right track." CBO staff similarly facilitated primary care access. One 33-year-old woman explained how her local SSP helped connect PWID to primary care: "they have doctors that come here to do outreach things. If that was something that we were interested in we could sign up with them." Numerous participants also described being connected to their primary care doctors through methadone clinics.

Second, many participants discussed inconvenient and unreliable transportation options as challenges to accessing primary care, explaining how "most addicts don't have a vehicle," leaving them reliant on busses, rides from friends, or walking. One participant described missing appointments when rides "fell through" or when he missed the bus. For others, transportation costs were prohibitive, as explained by this 53-year-old man: "If you're using on a daily basis, you don't have money to take transportation... Every dollar people get, they use it for drugs." These transportation limitations were somewhat less significant in urban areas with a greater density of health services and more robust public transit. One man from an urban center said he could easily access nearby healthcare facilities: "the only thing that'd stop me is me, because I'm right on the bus line."

A few participants described transportation resources that facilitated healthcare access. One 31-year-old woman said the free ride service provided through her insurance was essential for accessing methadone and primary care: "What makes me go to my clinic is because I have automatic rides... If I didn't, then I wouldn't care as much." Other clinics provided monthly bus passes, which one participant described as "worth more than gold."

Third, some participants did not utilize primary care due to unavailability of local providers and long wait times. One man described how the unavailability of PCPs in his town made him seek alternatives: "I actually have attempted to find [a PCP] because I had an injury at work... And no one wanted to take new patients... I've had to go to walk-in clinics or the hospital, which is a pain." Another participant who did have a PCP described his experience as "horrible" because his doctor was so busy: "I can't get in to see him for two months [and] I can't wait two months." Several participants believed there were "not enough doctors" in their small towns, requiring them to travel into large cities. Another participant said it was "almost impossible" to access primary care locally, so he traveled an hour by bus to a PCP practicing in an urban center.

A final systemic-level barrier to primary care utilization was related to frequent physician turnover and difficulty forming trusting patient-provider relationships. One participant described never seeing the same PCP more than once: "By the time I have to go to a second appointment, the first [doctor] is already gone." Similarly, this 41-year-old man described how frequent turnover made him reluctant to return to primary care: "[Doctors] leave, and they give me someone else, and I have to start all over again, so I'm done. I want someone that's been there long-term and that's not going to go anywhere sometime soon."

\section{DISCUSSION}

This study provides insight into the multilevel barriers to primary care utilization experienced by PWID in the Northeast US, a region experiencing a substantial burden of injection drug use and related public health consequences. ${ }^{37-39}$ While some participants did not perceive a current need for primary care, others were motivated to improve their health but had difficulty prioritizing healthcare over the competing demands of finding shelter, earning money, and locating drugs to avoid withdrawal. Many had experienced stigma in healthcare settings that made them reluctant to access services. Additional systemic barriers included difficulty navigating healthcare systems, unreliable transportation options, long wait times, and provider turnover. While not unique to PWID, these barriers can be especially challenging for PWID to overcome, considering the prevalence of homelessness, low socioeconomic status, and incarceration in this population. ${ }^{45}$ Importantly, the individual-, interpersonal-, and systemic-level barriers described in this study often coexist and may compound one another, making it even more difficult for PWID to access care.

Our findings support and expand upon previous studies identifying systemic-level factors, continued drug use, and strained patient-provider relationships as barriers to Hepatitis C screening and treatment for PWID. ${ }^{46-48}$ Importantly, building on existing research with providers, ${ }^{49,50}$ we provide new insights into key barriers and facilitators from the patient perspective. Facilitators described by PWID included appointment reminders, flexible hours, case management, referral systems with CBOs, transportation support, and addiction medicine-trained providers. Based on these facilitators and findings from the literature, we propose a number of strategies to better engage PWID in primary care, including reducing barriers within existing clinical settings and offering services in alternative settings, as described below and in Table 2 .

Important strategies that can be implemented within existing clinical settings include case management and transportation supports. Text-message reminders benefit individuals with phone access, ${ }^{51}$ and web-based reminders could help patients who have Internet but not phone access. Of note, these strategies benefit PWID who already want or have primary care access but face difficulties making or keeping appointments. To reach a broader population of PWID who avoid primary care entirely, it may be important to engage with PWID by offering clinical care at locations where they already access services, including SSPs, methadone clinics, and medically managed withdrawal programs. Study participants described generally positive relationships with PCPs 
Table 2 Barriers to Primary Care Utilization Among People Who Inject Drugs and Corresponding Strategies to Improve Engagement

\begin{tabular}{|c|c|c|}
\hline $\begin{array}{l}\text { Socio-ecological } \\
\text { level }\end{array}$ & Barriers & Strategies to improve engagement \\
\hline Individual & $\begin{array}{l}\text { Perceived lack of preventive healthcare needs } \\
\text { Competing priorities (e.g., homelessness, } \\
\text { finding drugs to avoid withdrawal) }\end{array}$ & $\begin{array}{l}\text { - Offer primary care services or linkage in settings PWID already visit (e.g., } \\
\text { SSPs, methadone clinics, inpatient hospitalizations). } \\
\text { - Offer flexible appointment times and drop-in hours to accommodate } \\
\text { unpredictable schedules. } \\
\text { - Provide text/phone appointment reminders. Web-based reminders may reach } \\
\text { patients with Internet access but not cellular data. } \\
\text { - Engage support persons in patients' lives to help remember appointments. }\end{array}$ \\
\hline Interpersonal & $\begin{array}{l}\text { Stigma and discrimination in healthcare } \\
\text { settings }\end{array}$ & $\begin{array}{l}\text { - Normalize a compassionate, non-judgmental PCP approach to reduce } \\
\text { experiences of stigma. } \\
\text { - Support providers in seeking training in addiction medicine (e.g., fellowship, } \\
\text { didactics, buprenorphine waiver). } \\
\text { - Require education about SUDs as part of Internal Medicine, Family Medicine, } \\
\text { and Psychiatry residency programs. } \\
\text { - Train front-line staff (e.g., front-desk staff, security, medical assistants) in } \\
\text { strategies to reduce stigma. } \\
\text { - Launch institution-wide campaigns to reduce stigmatizing language (e.g., } \\
\text { "person with substance use disorder" instead of "addict" or "junkie"). } \\
\text { - Employ community health workers and other individuals with lived } \\
\text { experience with substance use to decrease mistrust and increase comfort. } \\
\text { - Offer harm reduction services within primary care. }\end{array}$ \\
\hline \multirow[t]{4}{*}{ Systemic } & $\begin{array}{l}\text { Difficulty navigating the healthcare system } \\
\text { (e.g., insurance, making appointments) }\end{array}$ & $\begin{array}{l}\text { - Employ case managers to assess the needs of PWID and provide linkage and } \\
\text { navigation to primary care, insurance, and other resources. } \\
\text { - Engage PWID in CBOs (e.g., SSPs) where they already access services. } \\
\text { - Increase clinical service provision within CBOs. } \\
\text { - Integrate medications opioid use disorder within primary care clinics. }\end{array}$ \\
\hline & $\begin{array}{l}\text { Unreliable or inconvenient transportation to } \\
\text { appointments }\end{array}$ & $\begin{array}{l}\text { - Provide free shuttles or public transit passes. } \\
\text { - Enroll patients in insurance-based transportation benefits } \\
\text { - Partner with ride-sharing services to offer free or subsidized transportation. }\end{array}$ \\
\hline & $\begin{array}{l}\text { Lack of providers or long wait times to make } \\
\text { an appointment }\end{array}$ & $\begin{array}{l}\text { - Advocate for large-scale investment in the primary care work force (e.g., loan } \\
\text { forgiveness and reimbursement reform) at state and national levels. } \\
\text { - Implement low-barrier, transitional bridge clinics for rapid initiation of } \\
\text { medications for opioid use disorders and primary care linkage. }\end{array}$ \\
\hline & $\begin{array}{l}\text { Frequent provider turnover prevents formation } \\
\text { of trusting relationships }\end{array}$ & $\begin{array}{l}\text { - Normalize discussions between patients and providers about team composition } \\
\text { and continuity. } \\
\text { - Empower patients to ask if their PCPs plan to stay in practice long-term. }\end{array}$ \\
\hline
\end{tabular}

they met through CBOs and SSPs, perhaps due to increased provider experience caring for PWID.

Tailoring clinic scheduling, where possible, could also help increase primary care utilization among PWID. Many participants preferred flexible or drop-in appointments, though these are not widespread. A recent qualitative study ${ }^{52}$ tested PWID receptiveness to care at a low-barrier bridge clinic (i.e., drop-in clinic providing harm reduction services and initiation of MOUD). Patients appreciated the flexibility of the program and compassionate providers. Similar low-barrier models have proven successful for treatment retention among high-need patients with HIV. ${ }^{53}$ While fulltime drop-in hours can present challenges to fulfilling provider billing requirements, these innovative models likely increase accessibility and warrant consideration.

In addition to flexible scheduling, primary care settings must be welcoming to PWID. Our study and others have identified stigma and discrimination as significant barriers to healthcare. ${ }^{35,36}$ Participants described greater comfort with addiction-trained providers, which may relate to the availability and integration of buprenorphine in these providers' practices. Increased fellowship training in addiction medicine is beneficial, but alone this strategy alone is unlikely to address the systemic stigma surrounding addiction. More PCPs should be equipped to treat SUD (e.g., by providing buprenorphine); however, addiction education in internal and family medicine residency programs is lacking. ${ }^{54-56}$ Dedicated training regarding SUD screening, diagnosis, and treatment during residencies could better prepare PCPs to care for PWID. ${ }^{57-59}$ Hospital campaigns to train front-line staff and reduce providers' stigmatizing language in favor of person-first language may also help reduce the stigma experienced by PWID. ${ }^{60,61}$

Primary care for PWID is important because it provides a potential "one-stop shop" for addressing complex healthcare needs. For a population experiencing numerous healthcare barriers, it is beneficial to co-locate services and minimize the need to see multiple providers. ${ }^{62,63}$ PCPs can help manage chronic health conditions and offer important preventive health services including vaccinations, contraception, screening and treatment for infectious diseases, and MOUD. While uptake of PrEP for PWID has remained low, PrEP can be prescribed by PCPs. ${ }^{20,40}$ Increasingly, patients are also able to receive effective treatment for SUDs in primary care clinics through prescription of naltrexone and buprenorphine. ${ }^{24,64}$ The number of providers waivered to prescribe buprenorphine increased by $175 \%$ from 2016 to 2018 , though $35 \%$ of US counties did not have a single buprenorphine prescriber as of $2018{ }^{65}$ More PCPs could undergo buprenorphine training to increase access to MOUD within primary care settings; alternatively, federal regulations could be amended to no longer 
require special training for buprenorphine prescribing, thereby lowering barriers for PCPs. It is equally important to engage PWID who are not interested in changing their substance use by offering harm reduction services, including overdose prevention counseling, naloxone distribution, and counseling on safer injection practices, all of which can be accomplished by PCPs ${ }^{66}$ SSP regulations vary widely by state, ${ }^{67}$ and PCPs can facilitate safer injection practices by prescribing syringes and alcohol swabs ${ }^{68}$ or by distributing sterile injection equipment. By offering many services in one location, primary care could play an important role in improving health for PWID.

This study had several limitations. First, the HIV prevention-focused research from which we derived data was not explicitly designed to explore primary care experiences and we may have missed opportunities to probe more systematically about all important aspects of this topic (e.g., MOUD integration into primary care). However, healthcare utilization emerged as a key topic of interest in the first phase of our research and we developed specific questions for the second phase to explore these topics more extensively. While some participants discussed having addiction medicinetrained providers, who may have been more likely to offer buprenorphine, it was interesting that buprenorphine access was not explicitly described as a facilitator of primary care. This gap may reflect the traditional siloing of SUD treatment and primary care and highlights a need for additional research and efforts to better integrate MOUD into primary care.

Second, our sampling of PWID was limited to two states in the Northeast US with the early expansion of Medicaid, and most participants in our sample had health insurance. Our findings may not generalize to lower-resourced areas, and further research is warranted in states with reduced access to public insurance and health services. However, our large sample $(n=78)$ recruited from 16 urban and non-urban communities across two states captured diverse experiences that may still be helpful for efforts to increase access to low-barrier primary care in this marginalized population.

In conclusion, improving access to primary care for PWID will be critical to addressing the health harms from opioid and polysubstance use in the USA. Increased primary care utilization among PWID could limit the spread of infectious diseases, increase uptake of medications for opioid use disorder, and reduce morbidity and mortality. The facilitators described in this study draw upon real success stories with primary care among PWID and could guide interventions for increasing primary care utilization and strengthening patient-provider relationships. We offer a number of strategies that clinics and other service providers may implement; however, future research is needed to assess the feasibility and efficacy of these strategies to increase primary care utilization and satisfaction among PWID. Interventions should work toward the shared goal of providing accessible, non-stigmatizing primary care to PWID to improve individual patient and public health outcomes.
Acknowledgments: The authors wish to thank the participants and organizations involved in this research for making it possible.

Corresponding Author: Angela R. Bazzi, PhD, MPH; Department of Community Health Sciences, Boston University School of Public Health, Boston, MA 02118, USA (e-mail: abazzi@bu.edu).

Funding This research was funded by the Providence/Boston Center for AIDS Research (P3OAIO42853), NIH/NIDA grant KO1DA043412, the Boston University Peter Paul Career Development Professorship, and the Boston University School of Medicine Medical Student Summer Research Program.

\section{Compliance with Ethical Standards:}

Participants provided informed consent and received $\$ 25$ for participating. The Brown and Boston University Institutional Review Boards approved all study protocols and provided a waiver of documentation of consent.

Conflict of Interest: The authors declare that they do not have a conflict of interest.

\section{REFERENCES}

1. Degenhardt L, Peacock A, Colledge S, et al. Global prevalence of injecting drug use and sociodemographic characteristics and prevalence of $\mathrm{HIV}, \mathrm{HBV}$, and $\mathrm{HCV}$ in people who inject drugs: a multistage systematic review. Lancet Glob Heal. 2017;5(12):e1192-e1207. doi:https://doi.org/ 10.1016/S2214-109X(17)30375-3

2. Scholl L, Seth P, Kariisa M, Wilson N, Baldwin G. Drug and OpioidInvolved Overdose Deaths - United States, 2013-2017. Morb Mortal Wkly Rep. 2018;67(5152). https://doi.org/10.15585/mmwr. mm6751521e1

3. Mathers BM, Degenhardt L, Bucello C, Lemon J, Wiessing L, Hickman M. Mortality among people who inject drugs: a systematic review and meta-analysis. Bull World Health Organ. 2013;91(2):102-123. doi:https://doi.org/10.2471/BLT.12.108282

4. Binswanger IA, Kral AH, Bluthenthal RN, Rybold DJ, Edlin BR. High Prevalence of Abscesses and Cellulitis Among Community-Recruited Injection Drug Users in San Francisco. Clin Infect Dis. 2000;30(3):579581. doi:https://doi.org/10.1086/313703

5. HIV Among People Who Inject Drugs. Centers for Disease Control and Prevention. Available at: https://www.cdc.gov/hiv/group/hiv-idu.html. Published March 15, 2020.

6. Surveillance for Viral Hepatitis - United States, 2017. Center for Disease Control and Prevention (CDC). Available at: https://www.cdc.gov/hepatitis/statistics/2017surveillance/index.htm. Published 2019. Accessed February 18, 2020.

7. Compton WM, Thomas YF, Stinson FS, Grant BF. Prevalence, correlates, disability, and comorbidity of DSM-IV drug abuse and dependence in the United States: Results from the national epidemiologic survey on alcohol and related conditions. Arch Gen Psychiatry. 2007;64(5):566-576. doi:https://doi.org/10.1001/archpsyc.64.5.566

8. Goldner EM, Lusted A, Roerecke M, Rehm J, Fischer B. Prevalence of Axis-1 psychiatric (with focus on depression and anxiety) disorder and symptomatology among non-medical prescription opioid users in substance use treatment: Systematic review and meta-analyses. Addict Behav. 2014;39(3):520-531. doi:https://doi.org/10.1016/j.addbeh. 2013.11.022

9. Visconti AJ, Sell J, Greenblatt AD. Primary Care for Persons Who Inject Drugs. Am Fam Physician. 2019;99(2): 109-116.

10. Azar P, Wood E, Nguyen P, et al. Drug use patterns associated with risk of non-adherence to antiretroviral therapy among HIV-positive illicit drug users in a Canadian setting: a longitudinal analysis. BMC Infect Dis. 2015;15(1): 193. doi:https://doi.org/10.1186/s12879-015-0913-0

11. Zeremski M, Zibbell JE, Martinez AD, Kritz S, Smith BD, Talal AH. Hepatitis $\mathrm{C}$ virus control among persons who inject drugs requires overcoming barriers to care. World $J$ Gastroenterol. 2013;19(44):78467851. doi:https://doi.org/10.3748/wjg.v19.i44.7846 
12. Olsen A, Banwell C, Madden A. Contraception, punishment and women who use drugs. BMC Womens Health. 2014;14(1):5. doi:https://doi.org/ 10.1186/1472-6874-14-5

13. Matusiewicz AK, Melbostad HS, Heil SH. Knowledge of and concerns about long-acting reversible contraception among women in medicationassisted treatment for opioid use disorder. Contraception. 2017;96(5):365-369. doi:https://doi.org/10.1016/j.contraception.2017. 07.167

14. Heil SH, Jones HE, Arria A, et al. Unintended pregnancy in opioidabusing women. J Subst Abuse Treat. 2011;40(2):199-202. doi:https:// doi.org/10.1016/j.jsat.2010.08.011

15. Iversen J, Page K, Madden A, Maher L. HIV, HCV, and health-related harms among women who inject drugs: Implications for prevention and treatment. J Acquir Immune Defic Syndr. 2015;69(Suppl 2):S176-S181. doi:https://doi.org/10.1097/QAI.0000000000000659

16. Collier MG, Drobeniuc J, Cuevas-Mota J, Garfein RS, Kamili S, Teshale EH. Hepatitis A and B among young persons who inject drugsVaccination, past, and present infection. Vaccine. 2015;33(24):28082812. doi:https://doi.org/10.1016/j.vaccine.2015.04.019

17. Al-Tayyib AA, Thiede H, Burt RD, Koester S. Unmet Health Care Needs and Hepatitis C Infection Among Persons Who Inject Drugs in Denver and Seattle, 2009. Prev Sci. 2015;16(2):330-340. doi:https://doi.org/10. 1007/s11121-014-0500-4

18. Epstein RL, Wang $\mathbf{J}$, Hagan $\mathbf{L}$, et al. Hepatitis C Virus Antibody Testing among 13- to 21-Year-Olds in a Large Sample of US Federally Qualified Health Centers. JAMA. 2019;322(22):2245-2248. doi:https://doi.org/10. 1001/jama.2019.16196

19. Garner W, Wilson BM, Beste L, Maier M, Ohl ME, Van Epps P. Gaps in preexposure prophylaxis uptake for HIV prevention in the Veterans Health Administration. Am J Public Health. 2018;108(Suppl 4):S305S310. doi:https://doi.org/10.2105/AJPH.2018.304788

20. McFarland W, Lin J, Santos GM, Arayasirikul S, Raymond HF, Wilson E. Low PrEP Awareness and Use Among People Who Inject Drugs, San Francisco, 2018. AIDS Behav. September 2019:1-4. doi:https://doi.org/ 10.1007/s10461-019-02682-7

21. Chi FW, Parthasarathy S, Mertens JR, Weisner CM. Continuing Care and Long-Term Substance Use Outcomes in Managed Care: Early Evidence for a Primary Care-Based Model. Psychiatr Serv. 2011;62(10): 1194-1200. doi:https://doi.org/10.1176/ps.62.10. pss6210_1194

22. Facente SN, Burk K, Eagen $\mathbf{K}$, Mara ES, Smith AA, Lynch CS. New Treatments Have Changed the Game: Hepatitis C Treatment in Primary Care. Infect Dis Clin North Am. 2018;32(2):313-322. doi:https://doi.org/ 10.1016/j.idc.2018.02.012

23. Wade AJ, Doyle JS, Gane E, et al. Outcomes of Treatment for Hepatitis C in Primary Care, Compared to Hospital-based Care: A Randomized, Controlled Trial in People Who Inject Drugs. Clin Infect Dis. June 2019:17. doi:https://doi.org/10.1093/cid/ciz546

24. Edelman EJ, Oldfield BJ, Tetrault JM. Office-Based Addiction Treatment in Primary Care: Approaches That Work. Med Clin North Am. 2018;102(4):635-652. doi:https://doi.org/10.1016/j.mcna.2018.02.007

25. Cole ES, DiDomenico E, Cochran G, et al. The Role of Primary Care in Improving Access to Medication-Assisted Treatment for Rural Medicaid Enrollees with Opioid Use Disorder. J Gen Intern Med. 2019;34(6):936943. doi:https://doi.org/10.1007/s11606-019-04943-6

26. O'Connor PG, Oliveto AH, Shi JM, et al. A randomized trial of buprenorphine maintenance for heroin dependence in a primary care clinic for substance users versus a methadone clinic. Am $\mathrm{J} \mathrm{Med}$. 1998;105(2):100-105. doi:https://doi.org/10.1016/S0002-9343(98) 00194-6

27. Artenie AA, Jutras-Aswad D, Roy, et al. Visits to primary care physicians among persons who inject drugs at high risk of hepatitis $\mathrm{C}$ virus infection: Room for improvement. J Viral Hepat. 2015;22(10):792-799. doi:https:// doi.org/10.1111/jvh.12393

28. Chitwood DD, Sanchez J, Comerford M, McCoy CB. Primary preventive health care among injection drug users, other sustained drug users, and non-users. Subst Use Misuse. 2001;36(6-7):807-824.

29. Ries R, Krupski A, West II, et al. Correlates of opioid use in adults with self-reported drug use recruited from public safety-net primary care clinics. J Addict Med. 2015;9(5):417-426. doi:https://doi.org/10.1097/ ADM.0000000000000151

30. Choi S, Biello KB, Bazzi AR, Drainoni M-L. Age differences in emergency department utilization and repeat visits among patients with opioid use disorder at an urban safety-net hospital: A focus on young adults. Drug Alcohol Depend. 2019;200:14-18. doi:https://doi.org/10. 1016/j.drugalcdep.2019.02.030
31. D'Onofrio G, O'Connor PG, Pantalon M V., et al. Emergency department-initiated buprenorphine/naloxone treatment for opioid dependence: A randomized clinical trial. JAMA. 2015;313(16):1636-1644. doi:https://doi.org/10.1001/jama.2015.3474

32. Herring A. CA Bridge Toolkit. Available at: https://www.bridgetotreatment.org/.

33. A Matter of Urgency: Reducing Emergency Department Overuse.; 2010. Available at: https://www.nehi.net/writable/publication_files/file/nehi ed_overuse_issue_brief_032610finaledits.pdf. Accessed December 23, 2019.

34. Nambiar D, Stoové M, Dietze P. A cross-sectional study describing factors associated with utilisation of GP services by a cohort of people who inject drugs. BMC Health Serv Res. 2014;14(1):308. doi:https://doi.org/ 10.1186/1472-6963-14-308

35. Biancarelli DL, Biello KB, Childs E, et al. Strategies used by people who inject drugs to avoid stigma in healthcare settings. Drug Alcohol Depend. 2019;198:80-86. doi:https://doi.org/10.1016/j.drugalcdep.2019.01.037

36. Paquette CE, Syvertsen JL, Pollini RA. Stigma at every turn: Health services experiences among people who inject drugs. Int $J$ Drug Policy. 2018;57:104-110. doi:https://doi.org/10.1016/j.drugpo.2018.04.004

37. Kariisa M, Scholl L, Wilson N, Seth P, Hoots B. Drug Overdose Deaths Involving Cocaine and Psychostimulants with Abuse Potential - United States, 2003-2017. Morb Mortal Wkly Rep. 2019;68(17):388-395. doi:https://doi.org/10.15585/mmwr.mm6817a3

38. Barocas JA, Wang J, Marshall BDL, et al. Sociodemographic factors and social determinants associated with toxicology confirmed polysubstance opioid-related deaths. Drug Alcohol Depend. 2019;200:59-63. doi:https://doi.org/10.1016/j.drugalcdep.2019.03.014

39. Cranston K, Alpren C, John B, et al. Notes from the Field: HIV Diagnoses Among Persons Who Inject Drugs - Northeastern Massachusetts, 2015-2018. Morb Mortal Wkly Rep. 2019;68(10):253-254. doi:https://doi.org/10.15585/mmwr.mm6810a6

40. Bazzi AR, Biancarelli DL, Childs E, et al. Limited Knowledge and Mixed Interest in Pre-Exposure Prophylaxis for HIV Prevention among People Who Inject Drugs. AIDS Patient Care STDS. 2018;32(12):529-537. doi:https://doi.org/10.1089/apc.2018.0126

41. Patton MQ. Qualitative Research and Evaluation Methods. 3rd ed. Thousand Oaks, CA: Sage Publications; 2002. doi:https://doi.org/10. $2307 / 330063$

42. Johnson, JC; Arluke A. Selecting Ethnographic Informants. Newbury Park, CA: Sage Publications; 1992. doi:https://doi.org/10.1093/sf/70.4. 1158

43. Guest G, Bunce A, Johnson L. How Many Interviews Are Enough? An Experiment with Data Saturation and Variability. Field methods. 1995; 18(1):59-82. doi:https://doi.org/10.1177/1525822X05279903

44. Bronfenbrenner U. The Ecology of Human Development: Experiments by Nature and Design. Cambridge, MA: Harvard University Press; 1979.

45. Galea S, Vlahov D. Social Determinants and the Health of Drug Users: Socioeconomic Status, Homelessness, and Incarceration. Public Health Rep. 2002;117(Supplement 1):S135-S145.

46. Barocas JA, Brennan MB, Hull SJ, Stokes S, Fangman JJ, Westergaard RP. Barriers and facilitators of hepatitis C screening among people who inject drugs: a multi-city, mixed-methods study. Harm Reduct J. 2014;11(1). https://doi.org/10.1186/1477-7517-11-1

47. Swan D, Long J, Carr O, et al. Barriers to and Facilitators of Hepatitis C Testing, Management, and Treatment Among Current and Former Injecting Drug Users: A Qualitative Exploration. AIDS Patient Care STDS. 2010;24(12):753-762. doi:https://doi.org/10.1089/apc.2010.0142

48. Childs E, Assoumou SA, Biello KB, et al. Evidence-based and guidelineconcurrent responses to narratives deferring $\mathrm{HCV}$ treatment among people who inject drugs. Harm Reduct J. 2019;16(1):14. doi:https://doi. org/10.1186/s12954-019-0286-6

49. Lang $\mathbf{K}$, Neil J, Wright J, Dell CA, Berenbaum S, El-Aneed A. Qualitative investigation of barriers to accessing care by people who inject drugs in Saskatoon, Canada: Perspectives of service providers. Subst Abus Treat Prev Policy. 2013;8(1):35. doi:https://doi.org/10.1186/ 1747-597X-8-35

50. Reyre A, Jeannin R, Largueche M, Moro MR, Baubet T, Taieb 0 . Overcoming professionals' challenging experiences to promote a trustful therapeutic alliance in addiction treatment: A qualitative study. Drug Alcohol Depend. 2017;174:30-38. doi:https://doi.org/10.1016/j.drugalcdep.2017.01.015

51. Junod Perron N, Dominicé Dao M, Kossovsky MP, et al. Reduction of missed appointments at an urban primary care clinic: A randomised controlled study. BMC Fam Pract. 2010;11(1):79. doi:https://doi.org/10. 1186/1471-2296-11-79 
52. Snow RL, Simon RE, Jack HE, Oller D, Kehoe L, Wakeman SE. Patient experiences with a transitional, low-threshold clinic for the treatment of substance use disorder: A qualitative study of a bridge clinic. $J$ Subst Abuse Treat. 2019;107:1-7. doi:https://doi.org/10.1016/j.jsat.2019.09. 003

53. Dombrowski JC, Ramchandani M, Dhanireddy S, Harrington RD, Moore A, Golden MR. The Max Clinic: Medical Care Designed to Engage the Hardest-to-Reach Persons Living with HIV in Seattle and King County, Washington. AIDS Patient Care STDS. 2018;32(4):149-156. doi:https://doi.org/10.1089/apc.2017.0313

54. Wakeman SE, Baggett M V., Pham-Kanter G, Campbell EG. Internal medicine residents training in substance use disorders: A survey of the quality of instruction and residents self-perceived preparedness to diagnose and treat addiction. Subst Abus. 2013;34(4):363-370. doi:https://doi.org/10.1080/08897077.2013.797540

55. Tesema L, Marshall J, Hathaway R, et al. Training in office-based opioid treatment with buprenorphine in US residency programs: A national survey of residency program directors. Subst Abus. 2018;39(4):434-440. doi:https://doi.org/10.1080/08897077.2018.1449047

56. Tong S, Sabo R, Aycock R, et al. Assessment of Addiction Medicine Training in Family Medicine Residency Programs: A CERA Study. Fam Med. 2017;49(7):537-543.

57. Wakeman SE, Pham-Kanter G, Baggett M V, Campbell EG. Medicine Resident Preparedness to Diagnose and Treat Substance Use Disorders: Impact of an Enhanced Curriculum. Subst Abus. 2015;36(4):427-433. doi:https://doi.org/10.1080/08897077.2014.962722

58. O'Connor PG, Nyquist JG, McLellan AT. Integrating addiction medicine into graduate medical education in primary care: The time has come. Ann Intern Med. 2011;154(1):56-59. doi:https://doi.org/10.7326/0003-4819 154-1-201101040-00008

59. Taylor JL, Rapoport AB, Rowley CF, Mukamal KJ, Stead W. An opioid overdose curriculum for medical residents: Impact on naloxone prescribing, knowledge, and attitudes. Subst Abus. 2018;39(3):371-376. doi:https://doi.org/10.1080/08897077.2018.1439800

60. Grayken Center for Addiction. Words Matter Pledge. Available at: https:// www.bmc.org/addiction/reducing-stigma. Accessed March 26, 2020.
61. Kelly JF, Westerhoff CM. Does it matter how we refer to individuals with substance-related conditions? A randomized study of two commonly used terms. Int J Drug Policy. 2010;21(3):202-207. doi:https://doi.org/ 10.1016/j.drugpo.2009.10.010

62. Bachireddy C, Soule MC, Izenberg JM, Dvoryak S, Dumchev K, Altice FL. Integration of health services improves multiple healthcare outcomes among HIV-infected people who inject drugs in Ukraine. Drug Alcohol Depend. 2014;134(1):106-114. doi:https://doi.org/10.1016/j.drugalcdep.2013.09.020

63. Centers for Disease Control. Integrated prevention services for HIV infection, viral hepatitis, sexually transmitted diseases, and tuberculosis for persons who use drugs illicitly: summary guidance from CDC and the U.S. Department of Health and Human Services. MMWR Recomm Rep. 2012;61(RR-5): 1-40

64. LaBelle CT, Han SC, Bergeron A, Samet JH. Office-Based Opioid Treatment with Buprenorphine (OBOT-B): Statewide Implementation of the Massachusetts Collaborative Care Model in Community Health Centers. J Subst Abuse Treat. 2016;60:6-13. doi:https://doi.org/10. 1016/j.jsat.2015.06.010

65. Ghertner R. U.S. trends in the supply of providers with a waiver to prescribe buprenorphine for opioid use disorder in 2016 and 2018. Drug Alcohol Depend. 2019;204:107527. doi:https://doi.org/10.1016/j.drugalcdep.2019.06.029

66. Behar E, Bagnulo R, Coffin PO. Acceptability and feasibility of naloxone prescribing in primary care settings: A systematic review. Prev Med (Baltim). 2018;114:79-87. doi:https://doi.org/10.1016/j.ypmed.2018. 06.005

67. Syringe Service Program Laws. The Policy Surveillance Program, LawAtlas. Available at: http://lawatlas.org/datasets/syringe-services-programs-laws. Published August 1, 2019. Accessed March 26, 2020.

68. Rich JD, Mckenzie M, Macalino GE, et al. A Syringe Prescription Program to Prevent Infectious Disease and Improve Health of Injection Drug Users. J Urban Heal Bull New York Acad Med. 2004;81(1):122-134.

Publisher's Note Springer Nature remains neutral with regard to jurisdictional claims in published maps and institutional affiliations. 